\title{
Editorial
}

Nos encontramos en proceso de mejoramiento de las actividades académicas de nuestra Facultad de Arquitectura, de tal manera, que se ha intervenido en diferentes aspectos que permiten el desarrollo y superación hacia la calidad académica en la formación del futuro profesional de la arquitectura en Nicaragua.

Entre estos podemos mencionar, el avance en cuestión de la transformación curricular de la carrera de arquitectura, proceso que se lleva con mucha precisión y cuidado para tener la certeza de concluir con un currículo adecuado a la situación socio económico y cultural de nuestro país. Sin dejar a un lado la investigación, factor importante que nos lleva en dirección de generar una interacción del docente investigador y la formación del profesional con esencia de investigación, siendo esta práctica la que nos ha llevado a considerar el equilibrio entre la investigación y la publicación de los resultados de la misma.

Destacar especialmente el impulso que la universidad por medio de la dirección de investigación ha promovido creando la categoría de docentes investigadores y en esta primera convocatoria nuestra facultad ha dicho presente con la participación de los arquitectos Perla Sánchez y Erasmo Aguilar.

En este sentido, se ha venido fortaleciendo el trabajo de la primera Revista Científica ARQUITECTURA + en la Facultad de Arquitectura, con todas dificultades como todo proyecto que en un inicio no se le da el reconocimiento justo, pero avanzando con paso firme que ha brindado un impulso a la investigación desde la Universidad Nacional de Ingeniería y también con investigadores externos, definiendo la publicación de la producción académica científica de la Arquitectura Nicaragüense.

Poner en las manos de nuestros lectores los temas de la Arquitectura, el Urbanismo, el Patrimonio Cultural y la Construcción, tratados con metodología científica y cuyos resultados destacan tópicos relacionados con nuestra sociedad, tal es el ejemplo, del documento que está dirigido a la "Construcción Durable: una visión de futuro para Nicaragua", que destaca el uso del concreto como material base para que la inversión en la infraestructura cobre auge y confianza en la nueva cara de la capital. Otros temas relevantes como son "Recuperar la acera, salvar la vida urbana" y "Valoración Patrimonial Urbano Arquitectónico del Municipio de San Juan del Sur". 


\section{Arquitectura +}

ISSN: 2518-2943

www.revistas.uni.edu.ni/index.php?jo

urnal=arquitectura

Enfatizar la participación de colegas que se encuentran realizando investigaciones muy importantes en la dinámica de la arquitectura actual y comparten el conocimiento científico con artículos de calidad con temas "Un enfoque Neuro-psicológico en la investigación científica arquitectónica" y "Vivienda vernácula palafítica mayangna y miskitu de Nicaragua".

Finalizamos este segundo año de ARQUITECTURA +, entregando el cuarto número de nuestra revista, esperando seguir trabajando con mucho tesón y agradeciéndole a todos los que han aportado y apoyado esta iniciativa y trabajo. Seguimos contando con todos y cada uno de Uds. en el éxito de nuestra revista científica.

Arq. Luis Chávez Quintero

Director Editorial Arquitectura +

Decano Facultad de Arquitectura UNI, Nicaragua 